Chemical Geology - Elsevier Publishing Company, Amsterdam

Printed in The Netherlands

\title{
Discussion
}

\section{EUROPIUM ANOMALIES AND THE GENESIS OF BASALT: A DISCUSSION}

\author{
DAVID G. TOWELL, REGINA V. SPIRN and JOHN W. WINCHESTER
}

Department of Geology, Indiana University, Bloomington, Ind. (U.S.A.)

Yonkers, N.Y. (U.S.A.) 1

Department of Meteorology and Oceanography, University of Michigan, Ann Arbor,

Mich. (U.S.A.)

(Received November 15, 1968)

\section{SUMMARY}

The argument advanced by Philpotts and Schnetzler that europium anomalies in igneous rocks and minerals are mainly caused by crystal chemistry without control by oxidation-reduction reactions is refuted on the grounds that the two effects cannot reasonably be separated in a crystallizing igneous melt.

\section{DISCUSSION}

Had Philpotts and Schnetzler (1968) read our paper (Towell et al., 1965) more carefully before writing theirs, they might have recognized that the geochemistry of europium in igneous rocks is probably more complex than they propose by their simple argument. They propose that the redox potential of a melt does not play a major role in controlling the anomalous behavior of Eu and claim that it is due only to crystal chemistry effects. More careful reading also might have prevented the unfounded allegation that Towell et al. (1965) in a study of samples from the batholith of southern California overlooked or denied the role of crystal chemistry and ascribed the anomalies entirely to redox effects.

In our 1965 paper, we pointed out: "Ce and $\mathrm{Eu}$, which may have $\mathrm{Ce}^{4+}$ and $\mathrm{Eu}^{2+}$ states under certain conditions of oxidation potential or chemical environment, may become separated from the other rare earths through different crystal chemistry, and these abundances may therefore appear anomalous on our normalized curves." As an example of the interrelation between redox reactions and crystal chemistry, we pointed out that $\mathrm{Eu}$, in the form of $\mathrm{Eu}^{2+}$, can coprecipitate efficiently with insoluble sulfates of $\mathrm{Sr}^{2+}$ or $\mathrm{Ba}^{2+}$ even if the instantaneous concentration of $\mathrm{Eu}^{2+}$ in the liquid is small compared to $\mathrm{Eu}^{3+}$. The same reasoning might apply to preferential inclusion of $\mathrm{Eu}^{2+}$ in feldspars and other minerals. Obviously, redox control of the process does not imply complete reduction of Eu to the divalent state in the liquid phase at any one time. This point was apparently confusing to Philpotts and Schnetzler who, it seems, failed to understand the relationships between the partition of an element between species in a single liquid phase and the

\footnotetext{
${ }^{1}$ Private address: $270 \mathrm{~N}$ Broadway, Yonkers, N.Y. 10701 (U.S.A.).
} 
partition of species containing that element between different solid and liquid phases. This appears to be a plausible interpretation of their self-

contradictory statement that:". . Eu anomalies, while caused by the relative stability of divalent Eu, are controlled largely by crystal chemistry rather than by the redox conditions in the melt." It is a fundamental fact that the redox conditions impart the relative stability or instability to the divalent $\mathrm{Eu}$ in the melt. The crystal chemistry of the solids that crystallize from the melt determines the extent to which the available $\mathrm{Eu}^{2+}$ is accommodated, rejected, or preferentially accumulated by these crystals. Thus, the roles of redox potential and crystal chemistry in producing a Eu anomaly cannot be separated.

By contrast, under the much more oxidizing conditions prevailing in sedimentary environments, the $\mathrm{Eu}^{2+} / \mathrm{Eu}^{3+}$ ratio in the liquid phase is so low that no Eu anomalies can be expected even where crystallizing solids could preferentially accommodate $\mathrm{Eu}^{2+}$ (Spirn, 1965, p.158).

Philpotts and Schnetzler's (1968) discussion of the Eu/Eu* ratios obtained from rocks of the batholith of southern California (Towell et al., 1965) merits comment. They point out that our observed decrease in feldspar $\mathrm{Eu} / \mathrm{Eu}^{*}$ (Eu observed/Eu predicted) ratios would have been expected in light of their later results on phenocrysts from other rocks if melts were becoming increasingly depleted in Eu. It should be noted that this was our original interpretation. Further, they state (Philpotts and Schnetzler, 1968): "Similarly, the $\mathrm{Eu} / \mathrm{Eu}$ * ratio for the plagioclase $\left(\mathrm{An}_{55}\right)$ from the San Marcos Gabbro is about 8.5 whereas for the plagioclase $\left(A n_{20}\right)$ from the leucogranite it is about 1.9; depletion of $\mathrm{Eu}$ in the melts is again indicated, rather than increasingly reducing conditions." At no time did we suggest nor imply that increasingly reducing conditions were present in residual melts. In fact, the opposite is expected. Indeed, more oxidizing conditions in residual melts would decrease the relative availability of $\mathrm{Eu}^{2+}$ and this might also play a role in reducing the positive Eu anomaly observed in the plagioclase from the leucogranite in addition to the effect of a general depletion of total Eu in these melts.

Towell et al. (1965) were also careful to point out that a Eu anomaly associated with a mineral fraction is not necessarily due entirely to the properties of the major mineral component because of the possibility of significant influence of accessory mineral phases remaining in the separated fractions. For this and other reasons, it is not easy to propose a specific mechanism for the anomalous behavior of Eu in rocks and minerals.

The existence of Eu anomalies and their possible significance were recognized by Goldschmidt many years ago (Goldschmidt, 1954). More recently, Chase et al. (1963) showed conclusively that Eu is distributed differently than other lanthanides in the minerals of three granites, being relatively enriched in feldspar and depleted in mica fractions of the same rock. These and succeeding workers have observed that granites often show relatively low $\mathrm{Eu}$ abundances whereas basalts, in general, do not show anomalies. In our 1965 paper, we reported a progressive loss of Eu with increasing differentiation index in the batholithic rocks, but Schilling and Winchester (1966) did not observe a similar loss of Eu during the evolution of Hawaiian volcanic rocks. Schilling (1966, pp.58-59) has shown that some steps in the evolution of the complete rare earth patterns in both the series studied by him and the one studied by us could have been produced by 
fractional crystallization of appropriate amounts of olivine (which is generally very poor in rare earths) and augite and plagioclase such as found in the gabbro of our series. Europium was anomalous in both of the latter two minerals, the augite having a negative Eu anomaly and plagioclase a positive one. Similarly, pyroxenes and plagioclases from an achondritic meteorite and a diabase analyzed by Philpotts and Schnetzler (1968) had negative and positive anomalies, respectively. The latter authors attributed the occurrence of positive Eu anomalies in the feldspars to the preferential inclusion of $\mathrm{Eu}^{2+}$ in addition to normal inclusion of $\mathrm{Eu}^{3+}$ along with the other rare earths. They suggest that negative Eu anomalies in the matrix pyroxenes probably are due to "their crystallizing in an immediate environment that was deficient in total Eu", without, however, proposing a mechanism that could produce such localized depletions.

Interestingly, Schnetzler and Philpotts (1967) obtained rare earth data on phenocrysts of olivine, augite and amphibole and associated matrix materials from a variety of porphyritic basic and ultrabasic igneous rocks which revealed no Eu anomalies. However, the coexistence of minerals with positive and negative Eu anomalies in non-porphyritic rocks is wellestablished. Removal of varying amounts of any pair or group of such minerals from reaction with the residual melt would leave the melt with either no net Eu anomaly or a negative one, or even a positive one. Similar effects could be produced in melts generated by anatexis (e.g. partial melting)

\section{CONCLUSIONS}

It is clear that the details of the mechanisms governing the generation of Eu anomalies are not well understood at this time. Nevertheless, it is also clear that the interplay between redox conditions in a melt, the crystal chemistry of the solid phases, the sequence in which the latter form and separate, and doubtlessly other factors all together control the evolution of Eu anomalies and the overall geochemistry of Eu.

The valuable data of Philpotts and Schnetzler (1968) should serve to stimulate continued interest in the importance and potential usefulness of Eu anomalies in igneous rocks and minerals.

\section{REFERENCES}

Chase, J.W., Winchester, J.W. and Coryell, C.D., 1963. Lanthanum, europium, and dysprosium distributions in igneous rocks and minerals. J. Geophys, Res.. 68: $567-575$.

Goldschmidt, V.M.: 1954. Geochemistry. Oxford University Press, London, 730 pp.

Philpotts, J.A. and Schnetzler, C.C., 1968. Europium anomalies and the genesis of basalt. Chem. Geol., 3: 5-13.

Schilling, J.G., 1966. Rare Earth Fractionation in Hawaiian Volcanic Rocks. Thesis, Dept. Geol. Geophys., Mass. Inst. Technol., Cambridge, Mass., 390 pp.

Schilling, J.G. and Winchester, J.W. 1966. Rare earths in Hawaiian basalts. Science, 153: 867-869.

Schnetzler, C.C. and Philpotts, J.A., 1967. Partition coefficients of rare-earth elements and barium between igneous matrix material and rock-formingmineral phenocrysts, 1. Proc. Intern. Assoc. Geochem. Cosmochem., in press. 
Spirn, R.V., 1965. Rare Earth Distributions in the Marine Environment. Thesis, Dept. Geol. Geophys., Mass. Inst. Technol., Cambridge, Mass., $165 \mathrm{pp}$.

Towell, D.G., Winchester, J.W. and Spirn, R.V., 1965. Rare-earth distributions in some rocks and associated minerals of the batholith of southern California. J. Geophys. Res., 70: 3485-3496.

\title{
EUROPIUM ANOMALIES AND THE GENESIS OF BASALT: A REPLY
}

\author{
JOHN A. PHILPOTTS and CHARLES C. SCHNETZLER
}

Planetology Branch, Goddard Space Flight Center, Greenbelt, Md. (U.S.A.)

(Received November 15, 1968)

We assure Towell, Spirn, and Winchester (Towell et al., 1969) that we read their interesting and valuable paper (Towell et al., 1965) with extraordinary care. It was, in fact, the major stimulus for many of the ideas expressed in our own paper (Philpotts and Schnetzler, 1968). We consider it most unfortunate that they have misunderstood, in part, the purpose and content of our paper. In their discussion (Towell et al., 1969), they have answered criticisms that we did not make or intend. Similarly, they apparently did not fully grasp some of the major arguments put forth in our paper, perhaps with less than optimum exposition. Some of the points raised by Towell et al. (1969) are irrelevant and others are restatements of points quite clearly made in their previous paper. Other points, however, require a response; these are now taken up essentially in the order in which they appeared in the discussion of Towell et al. (1969).

We did not claim that the anomalous behavior of $\mathrm{Eu}$ is due only to crystal chemistry effects. Similarly we did not make "the unfounded allegation that Towell et al. (1965). . .overlooked or denied the role of crystal chemistry and ascribed the anomalies entirely to redox effects." We consider it regrettable if our paper gave implications to this effect. However, there seems to be a difference of opinion as to the relative importance of crystal chemistry and redox effects, and, indeed, whether the two can be separated. As was previously noted (Philpotts and Schnetzler, 1968), Towell et al. (1965) suggested that "future study of Eu distributions may eventually be useful in estimating redox potentials." We also consider this to be a possibility; we believe that it is first necessary, however, to define quantitatively the much larger effects of crystal chemistry. An explanation of our "self-contradictory" statement that "Eu anomalies, while caused by the relative stability of divalent $\mathrm{Eu}$, are controlled largely by crystal chemistry rather than by redox conditions in the melt" is as follows: Redox conditions operative during the formation of igneous rocks are such that $E u$ (in contrast to the other rare-earth elements) shows significant stability in the divalent state. This is the basic cause of Eu anomalies in igneous rocks. However, we are not aware of any evidence that differences in redox conditions have affected the presence or size of europium anomalies in unaltered terrestrial igneous rocks or minerals. We do not deny that there 